\title{
Configurações
}

Revista de sociologia

\section{A família (d)escrita pelos jovens:permanência e mudança de modelos de paternidade}

The family through the eyes of the children: enduring and changing models of fatherhood

La famille (d)écrite par les jeunes : pérennité et changement des modèles de paternité

Maria das Dores Guerreiro, Ana Caetano e Eduardo Alexandre Rodrigues

\section{OpenEdition}

\section{Journals}

Edição electrónica

URL: http://journals.openedition.org/configuracoes/516

DOI: $10.4000 /$ configuracoes.516

ISSN: $2182-7419$

\section{Editora}

Centro de Investigação em Ciências Sociais

\section{Edição impressa}

Data de publição: 1 Janeiro 2008

Paginação: 115-126

ISSN: 1646-5075

\section{Refêrencia eletrónica}

Maria das Dores Guerreiro, Ana Caetano e Eduardo Alexandre Rodrigues, « A família (d)escrita pelos jovens:permanência e mudança de modelos de paternidade », Configurações [Online], 4 | 2008, posto online no dia 12 fevereiro 2012, consultado o 21 abril 2019. URL : http://journals.openedition.org/ configuracoes/516 ; DOI : 10.4000/configuracoes.516

Este documento foi criado de forma automática no dia 21 Abril 2019.

(c) CICS 


\section{A familia (d)escrita pelos jovens:permanência e mudança de modelos de paternidade}

The family through the eyes of the children: enduring and changing models of fatherhood La famille (d)écrite par les jeunes : pérennité et changement des modèles de paternité Rodrigues

\section{Introdução}

1 O campo da sociologia da família conta já com um importante e relevante corpo de trabalho problematizador dos múltiplos eixos analíticos que descrevem e decompõem as dinâmicas associadas à família. Umas das principais conclusões transversais a muitos destes trabalhos diz respeito ao dinamismo e à mutabilidade das formas de viver e entender a vida familiar. Desenvolver uma investigação que tenha por conceito central a família implica tomar em consideração a multiplicidade e a diversidade de noções associadas ao conceito, em particular as que resultam das próprias experiências e vivências familiares das pessoas.

2 Os debates em torno da natureza e da extensão das mudanças que estão a modi- ficar os modelos parentais surgem cada vez mais associados a discussões centradas na paternidade, ou seja, nas relações e identidades dos homens enquanto pais (Messner 1993; Sakka e Deliyanni-Kouimtzi 2006; Segal 1990, 1993; Tinklin et al. 2005). Os compromissos, relacionamentos e expectativas que se estabelecem entre pais e filhos num contexto de mudança rápida e diversidade crescente dos estatutos, "papéis" e posições sociais de mulheres e homens são, mais do que nunca, motivos de atenção por parte dos mais 
variados sectores, constituindo tema de múltiplos discursos: científicos, políticos, mediáticos, artísticos, etc.

3 Entre outros elementos que poderiam ser referidos, um dos mais importantes a destacar neste contexto é a forma como a proeminência recente dos vários temas centrados nas questões da paternidade acaba por revelar o cariz mais do que nunca aberto e problematizado das práticas e representações dos indivíduos - mães, pais, filhas, filhos e outros - quando perspectivados a partir das dinâmicas familiares de interacção, particularmente quando falamos do lugar dos homens nas famílias. A especial visibilidade contemporânea dessas práticas e representações articula-se como a existência de visões distintas e contraditórias (por vezes também altamente politizadas) a vários níveis: desde imagens contrastantes de "pais à antiga" e de "novos pais" à morte anunciada do papel de chefe-de-família que tem a seu cargo o sustento económico de esposa e filhos, ou desde a existência aplaudida de famílias mais "democráticas", onde o pai e a mãe partilham equitativamente as alegrias e os problemas da parentalidade e as tarefas domésticas, à persistente e largamente difundida ideia de que "a família está em crise", entre outras imagens mais ou menos pessimistas ou optimistas acerca das famílias contemporâneas (Leandro 2001). Contudo, e não obstante os cuidados que é necessário ter com esse conjunto vasto de perspectivas mais ou menos (des)informadas que esgrimem os seus argumentos muitas vezes baseadas em assunções não verificadas e conclusões algo apressadas, elas não devem ser simplesmente ignoradas, na medida em que reflectem, precisamente, uma atenção crescente relativamente a um conjunto de dinâmicas e fenómenos sociais que têm vindo a acontecer no âmbito articulado das relações familiares e de género.

4 Neste contexto, acreditamos que uma abordagem informada pela sociologia da família e por uma perspectiva crítica das relações de género pode contribuir para compreender de forma objectiva os processos de mudança que afectam a paternidade, e que têm a sua origem quer no interior, quer no exterior da família (Adams e Coltrane 2005; Connell 2002; Coltrane 2004; Coltrane e Adams 1997; Kimmel 2000).

5 Alguns dos factores mais importantes relacionados com os processos de construção social dos modelos culturais de paternidade e maternidade dizem respeito à proeminência da separação ideológica das esferas pública e privada operada no decorrer do século XX, que associou o homem à primeira e a mulher à segunda (Adams e Coltrane 2005): sendo uma construção ideológica e cultural, que retirou parte da sua força e durabilidade da conjugação de circunstâncias históricas específicas, esta concepção abrangente e dominante articula no seu âmago uma explicação e uma justificação da manutenção continuada de um sistema injusto de relações de género. A separação das esferas tem-se revelado particularmente resistente e permanece ainda hoje como uma força ideológica, quando os seus fundamentos são cada vez mais postos em causa em termos teóricos e políticos e em face das notáveis mudanças que se têm feito sentir nos domínios do trabalho e da família. Essas tensões têm origem na existência de esforços contraditórios de naturalização ou de luta contra o ideal cultural da separação das esferas pública e privada, simultaneamente vistas como distintas e complementares.

6 No âmbito da sociologia, Talcott Parsons (1965; ver também Parsons e Bales 1955) conceptualizou a separação das esferas e a consequente especialização dos papéis masculino e feminino como um factor crucial para o funcionamento "normal" da unidade familiar: o pai a providenciar os recursos económicos necessários para sustentar a família através do trabalho pago e a mãe responsável pelas tarefas domésticas, pelos cuidados dos 
filhos e pelo suporte emocional da família, eram vistos como desempenhando, de forma complementar, os papéis instrumental e expressivo, respectivamente. Assim, a teoria da dualidade de esferas pode ser encarada como articulando num sis- tema genderizado de desigualdade - simultaneamente a um nível individual e estrutural - um conjunto de concepções culturais acerca de modelos parentais "adequados" e "complementares" de maternidade e paternidade, mas também de conjugalidade (Torres 2001). Esta teoria, tal como foi elaborada por Parsons, provou ser influente, com muitos sociólogos da família a trabalharem, ainda hoje, dentro da tradição da teoria dos papéis sexuais, obviamente a partir de níveis diferentes de sofisticação conceptual.

7 As mudanças económicas e culturais que ocorreram nos últimos trinta anos contribuíram para a disrupção parcial da dualidade de esferas, sendo que a mais importante foi, provavelmente, o aumento da taxa de actividade feminina, também em Portugal (Almeida et al. 1998; Wall e Guerreiro 2005). Números crescentes de mulheres começaram a entrar no mercado de trabalho e a viver uma realidade quotidiana que, para algumas delas (pertencentes a famílias operárias, por exemplo), constituía desde há muito a norma: os dois membros do casal a trabalharem fora de casa. Esta mudança foi originada por um conjunto de mutações económicas mas também por alterações nas relações sociais de género, nas normas culturais e nos estilos de vida, e por factores de escolha e agência individual. Associada a outras dinâmicas societais relevantes (Blöss 2001; Tinklin et al. 2005) - tais como o movimento feminista de segunda vaga, taxas de fecundidade em declínio e outras alterações de natureza demográfica, reestruturações económicas de larga escala e emergência de uma economia de serviços -, a entrada das mulheres no mercado de trabalho contribuiu para originar mutações muito importantes na organização das vidas familiares e nas relações entre os vários protagonistas dessas vidas (Wall e Guerreiro 2005): à medida que começaram a ser diferentemente vividas e reflexivamente percepcionadas, as identidades e práticas em mudança de mães, pais, filhas e filhos tornaram-se, mais do que nunca, "problemáticas", e os seus significados mais fluidos e incertos.

8 Neste sentido, se a entrada de um número progressivamente maior de mulheres no mercado de trabalho contribuiu para a construção de relações de género mais igualitárias (Tinklin et al. 2005), também deu origem ao aparecimento de novas tensões e contradições na(s) vida(s) familiar(es) (Blöss 2001). As mulheres estão hoje em dia menos dependentes do casamento como forma de obter segurança económica e menos dispostas a participarem na "troca" entre trabalho doméstico não pago e o "papel" de "ganha-pão" desempenhado por um marido. Para além disso, e em face de múltiplas mudanças económicas e laborais de larga escala, já referidas, hoje em dia é bastante mais difícil que uma família possa depender de apenas um ordenado ganho pelo marido (Crompton 1999; Lewis 2001). O casamento ganhou assim um cariz mais opcional e contingente, os "papéis" parentais tornaram-se mais abertos e os significados, as representações e as práticas familiares mais negociáveis.

Consequentemente, hoje em dia os modelos culturais da parentalidade em geral e da paternidade em particular são, mais do que nunca, numerosos e híbridos. Os modos como os homens se vêem a si mesmos enquanto pais e se envolvem na vida quotidiana das suas famílias (em termos parentais e conjugais) são plurais, sendo afectados por múltiplos factores como a idade, a pertença étnica, a pertença de classe, a orientação sexual, mas também as circunstâncias variáveis das trajectórias biográficas e a configuração específica assumida por cada um dos contextos sociais que atravessam quotidianamente. 
Os homens são hoje em dia confrontados com pressões crescentes com origem em vários domínios (familiar, cultural, etc.) no sentido de se envolverem mais na vida familiar, nas tarefas domésticas e nos cuidados prestados aos filhos, de adoptarem atitudes e comportamentos mais adequados em termos emocionais e mais ajustados a uma relação mais próxima com os seus filhos e mais igualitária com as suas companheiras. Alguns homens estão a mudar nesse (e noutros) sentidos, mas muitos outros têm resistido à mudança.

Em termos de proeminência simbólica e centralidade normativa, o modelo cultural do pai emocionalmente distante que suporta economicamente a família parece estar a ser substituído pelo modelo cultural do "novo pai", mais envolvido com os filhos, mais carinhoso e emocionalmente aberto quer para as crianças quer para a com- panheira. Neste modelo cultural, os "novos pais" surgem envolvidos na vida da sua família de maneiras muito mais profundas do que aquelas que caracterizaram o envol- vimento dos seus próprios pais. Não obstante, a extensão e profundidade das mudanças efectivamente ocorridas nas formas de viver a paternidade são alvo de perspectivas variadas e, por vezes, contraditórias (LaRossa 1988; Marsiglio e Pleck 2005; Messner 1993; Segal 1990, 1993). As imagens culturais do "novo pai" têm sido criticadas como sendo representações idealizadas e desajustadas da realidade concreta da maioria das vivências familiares e também da configuração actual das relações de género. Para além disso, outras representações coexistem com a dos "novos pais", que emergem das tensões e contradições com que os homens têm que lidar enquanto pais.

11 Uma perspectiva de análise relativamente recente e muito frutuosa equaciona a construção social da paternidade com a construção social das masculinidades (Adams e Coltrane 2005; Coltrane 2004; Gerson 1997; Kimmel 2000; Lupton e Barclay 1997). Nesta linha de problematização, diferentes modelos de paternidade são articulados de forma não linear, complexa e dinâmica a variados estilos de paternidade, revelando assim a natureza aberta e multideterminada da família como instituição social, quer dizer, trazendo à luz as múltiplas conexões e processos de duplo sentido que se estabelecem entre a vida familiar, as estruturas sociais e económicas produtoras de diferença e desigualdade e as construções simbólicas. Determinados padrões sociais de conjugalidade, sexualidade, casamento, divórcio, trabalho doméstico, parentalidade e violência doméstica, por exemplo, característicos das sociedades contemporâneas, são entendi- dos como resultantes de uma articulação complexa e quotidianamente produzida entre as relações e interacções dos agentes concretos e a realidade estrutural de relações de género inigualitárias mas culturalmente validadas, pelo menos em parte. Pode assim construir-se uma perspectiva mais abrangente, por um lado, dos factores que contribuem para explicar a adopção, por parte dos pais, de determinados modelos simbólicos e comportamentais de conjugalidade e parentalidade e, por outro lado, dos constrangimentos que os homens enfrentam no que diz respeito à sua participação (ou falta dela) na vida familiar.

12 A família é uma instituição central na produção, reprodução, aprendizagem e representação das masculinidades. As representações e práticas de paternidade - em si mesmas constitutivas de uma dimensão importante de cada configuração individual de masculinidade - são cruciais neste contexto, na medida em que influenciam os processos através dos quais os rapazes se tornam homens. Um elemento fundamental destes últimos prende-se com a forma como eles são culturalmente "puxados" e "empurrados" em simultâneo para "fora" da vida familiar - os mesmos processos que "empurram" e 
"puxam" as raparigas para "dentro" da família -, o que contribui para a reprodução de relações de desigualdade de género mais vastas. Obviamente, os vários processos de socialização de género e de incorporação de valores e comportamentos considerados como masculinos não são simples ou lineares: são, sim, intrinsecamente contraditórios e originam tensões e conflitos, quer nas relações interpessoais, quer em termos individuais. É precisamente no domínio familiar que muitos homens são confrontados, talvez pela primeira vez e frequentemente de forma dramática, com as tensões e contradições inerentes ao seu estatuto privilegiado de género: sendo importantes na definição de concepções dominantes de masculinidade, os trabalhos (efectivos ou apenas normativamente expectáveis) da paternidade aparecem hoje muitas vezes, e mais do que nunca, em contradição com outras dimensões constitutivas da masculinidade. Como características gene- ricamente associadas à construção bem-sucedida da masculinidade, a independência, a assertividade, a distância e frieza emocionais e os padrões instrumentais de comporta- mento podem ser difíceis de conciliar com outras características cada vez mais associadas a uma vivência adequada das experiências da paternidade (e da conjugalidade também): o apoio desinteressado, carinhoso, próximo, a abertura emocional e a interdependência, etc. A "esfera pública" do trabalho, por exemplo - que continua a poder ser caracterizada, em dimensões cruciais, como um "mundo masculino" -, exige dos homens contemporâneos determinados tipos de investimento pessoal que muito dificilmente podem ser conciliados com maiores níveis de envolvimento e dedicação à vida familiar.

13 Aquilo que é por vezes apelidado de "crise da masculinidade" pode antes ser visto com vantagem, e em parte, como uma "linha de fractura" entre determinados ideais culturais de masculinidade, ainda prevalecentes em termos institucionais e nas ideias e comportamentos quotidianos de muitos homens e mulheres, e uma vida familiar frequentemente vivida como estando desprovida de alguns elementos essenciais (representados como "femininos"): carinho, atenção, altruísmo, dependência, abertura. Estamos em presença de tensões e dissonâncias associadas a uma equação entre os benefícios e os custos da masculinidade que praticamente todos os pais têm que resolver quotidiana- mente e ao longo das suas vidas (Adams e Coltrane 2005; Kimmel 2000).

Face aos processos de mudança aqui brevemente apresentados, o que é que os jovens portugueses, enquanto membros integrantes e participantes das dinâmicas familiares, têm a dizer acerca dos seus pais? De que forma os percepcionam? Como avaliam as relações que têm com eles? Que modelos de paternidade podem ser identificados e que representações e comportamentos os constituem? São esses modelos avaliados de forma diferente pelos jovens? O estudo que deu origem a esta comunicação teve precisamente por principal objectivo indagar em que medida as novas gerações apresentam indícios de que nas respectivas famílias estão a verificar-se mudanças nas formas de experienciar e representar a paternidade e a parentalidade em geral. Pretendeu-se, neste âmbito, dar voz aos jovens, captando as dinâmicas das realidades familiares através dos seus discursos. Enquanto agentes activos (Sarmento 2000) que contribuem para a construção da vida familiar e social, as suas opiniões e perspectivas sobre os processos de construção e mudança dos papéis parentais são fundamentais para compreender as famílias contemporâneas e as relações de género. Desenvolveu-se uma investigação composta por uma análise qualitativa e integrada de 792 composições escritas por jovens portugueses de todo o país, de ambos os sexos e com idades compreendidas entre os 11 e os 14 anos, acerca da família e das dinâmicas de mudança da parentalidade ${ }^{1}$ 


\section{Modelos culturais de paternidade: atitudes e comportamentos}

15 A forma como os jovens se referiram aos significados da família e às relações que se estabelecem entre os seus membros permitiu identificar quatro eixos analíticos que estruturam as suas representações sobre o que significa ser pai nas sociedades contemporâneas. Importa referir que as suas considerações articulam, por um lado, aquilo que é do nível das representações que circulam pelos mais diversos domínios societais sobre a paternidade e, por outro, as imagens que assentam nas suas próprias vivências familiares.

\section{a) A persistência de modelos tradicionais de paternidade}

16 A divisão tradicional do trabalho, doméstico e dos cuidados aos filhos, permanece como um padrão bastante vincado nas representações que estes jovens portugueses veiculam acerca da família: o pai como responsável pela segurança económica da família, através do trabalho pago, usualmente associado a uma mãe muito mais envolvida na vida familiar, que tem a seu cargo as tarefas domésticas e a satisfação das necessidades quotidianas dos filhos, não obstante o eventual desempenho em simultâneo de uma actividade profissional. Apesar de serem frequentes nas composições as referências às mães que trabalham, quer quando os jovens falam das suas próprias mães, quer em termos mais gerais - o que em si mesmo reflecte algo acerca das mudanças sociais ocorridas nas últimas décadas e que encontram tradução na realidade quotidiana de muitas famílias e no estado actual das relações de género -, a relação com o trabalho remunerado define ainda incomparavelmente mais as tarefas e responsabilidades do pai, que é visto como principal, embora cada vez menos único, provedor económico. Este modelo dicotomizado que prescreve "papéis" diferentes e simultaneamente complementares inclui um conjunto de imagens partilhadas e notavelmente persistentes dos homens como pais mais autoritários e rígidos do que as mães, emocionalmente mais distantes e até fisicamente ausentes, quer da companhia dos seus filhos, quer das suas parceiras.

"O pai é o elemento fundamental da família, como aquele que muitas vezes impõe mais respeito e temos-lhe por vezes até medo."

[Vera, 6.. ano, Braga]

"O homem é considerado o chefe-de-família. A última palavra é quase sempre do homem."

[Mariana, 9.․ ano, Lisboa]

"O pai está sempre mais virado para o trabalho, pois é ele que sustenta grande parte das vezes a família."

[João, $8 .{ }^{\circ}$ ano, Viseu]

"Os pais não nos dão carinho e a atenção especial como as mães."

[Rita, 6. ${ }^{\circ}$ ano, Braga]

"Os pais não demonstram muito bem o que sentem."

[Mariana, 8.. ano, Abrantes]

"Os pais, sendo homens, são mais agressivos e não têm paciência nenhuma."

[Ricardo, 6. ano, Braga] 


\section{b) A emergência de novos modelos parentais}

17 Ao mesmo tempo que alguns modelos mais tradicionais revelam uma persistência assinalável, deve igualmente ser notada a emergência de "novos" modelos culturais de paternidade. Nas suas composições, alguns jovens traçam retratos de pais carinhosos, presentes e envolvidos nas várias dimensões das suas vidas quotidianas e que, apesar de continuarem fortemente empenhados nas suas profissões no sentido de providenciarem a obtenção de segurança económica para as suas famílias, não deixam de ser caracterizados como os melhores amigos das suas crianças, sempre presentes quando são necessários para partilharem as alegrias e tribulações da vida familiar quotidiana. Nestes casos, as similaridades existentes entre os comportamentos e atitudes do pai e da mãe são sublinhadas pelos jovens, que utilizam frequentemente uma estratégia de realinhamento do desafio que lhes foi colocado pelo tema da composição: ao falarem e descreverem a forma como se relacionam com ambos os pais, transferem a questão dos papéis hipoteticamente diferentes de cada um para um plano de responsabilidades, obrigações e comportamentos semelhantes de parentalidade, necessariamente partilhados num quadro desejável, mais exigente e eventualmente mais democrático de vida familiar. Mais do que referente ao quotidiano da maioria das famílias, contudo, esse quadro a que as composições aludem é hoje principalmente um ideal normativo cada vez mais forte, em tensão permanente com o estado actual das estruturas e instituições que com- põem as relações de género e com as interacções e processos familiares do dia-a-dia.

"O papel dos pais também é educar os seus filhos, trabalhar, ajudar nas tarefas domésticas como, por exemplo, arrumar a casa, fazer o jantar e também levar os filhos à escola, ao médico, etc."

[João, Aveiro]

"Um pai a sério é aquele que dá atenção aos filhos e ajuda a sua mulher nos trabalhos domésticos."

[António, 6.a ano, Portalegre]

"Por isso nos nossos tempos a educação parte dos dois (pai e mãe), ninguém se julga superior a ninguém e assim os filhos levam uma educação mais equilibrada."

[Sílvia G., 9.․ano, Lisboa]

"Uns bons pais são aqueles que estão sempre presentes, ajudam os seus filhos, dãolhes carinho, amor e tudo o que uma criança precisa."

[Sílvia, 9.ํ ano, Lisboa]

\section{c) Modelos plurais de paternidade}

Um dos elementos de análise mais interessantes obtidos a partir das composições prendese com a presença de modelos híbridos, sincréticos e plurais de paternidade nas representações dos jovens. Esses modelos coexistem com imagens mais dicotómicas e unidimensionais - como as do "pai tradicional" e do "novo pai", por exemplo - e são indicadores de que nas interacções quotidianas com uma série de agentes (pais, irmãos, outros familiares, amigos, professores, media, etc.), os jovens deparam-se com atitudes e comportamentos múltiplos relativamente à paternidade, por vezes contraditórios entre si, outras vezes reforçando-se mutuamente, e não apenas entre os vários agentes mas também nos diversos contextos e tempos de vivência de cada um deles. Quer dizer que, por exemplo, os pais dos jovens tenderão certamente a agir e a relacionar-se com eles e com as suas companheiras de formas variáveis ao longo do tempo e dos contextos de interacção, reflectindo a influência de outras variáveis sociais na construção multideterminada dos modelos de paternidade que cada homem actualiza no decorrer da 
sua vida; os comportamentos e atitudes de paternidade são por isso dinâmicos e variáveis consoante as circunstâncias culturais e sociais que enquadram a existência de cada indivíduo. Os jovens também apreendem de forma perspicaz as tensões e desfasamentos que existem entre algumas das "novas" normas culturais da paternidade - maior envolvimento na vida familiar, disponibilidade e abertura emocionais, etc. - e as práticas e atitudes efectivas de muitos homens, incluindo as dos seus próprios pais. Indubitavelmente, os comportamentos de paternidade são, hoje em dia, mais complexos e híbridos do que nunca, variando de acordo com diversas linhas de diferenciação social idade, classe social, pertença étnica, orientação sexual, etc. - mas também de acordo com os mais variados contextos e tipos de interacção entre os pais, as suas companheiras e os seus filhos. Para além disso, as representações e práticas relativas à paternidade também variam ao longo do percurso de vida de cada homem e consoante as mais varia- das contingências da vida social, sendo afectadas por mudanças de âmbito alargado nas formas de vivenciar a família, o trabalho, o lazer, etc.

"Um pai normalmente é o que sustenta a casa, vai trabalhar e ao chegar a casa pouco auxilia a mulher nas tarefas domésticas, pois limita-se a sentar-se a ler o jornal ou ver televisão. Apesar de nem ser sempre assim! Muitos pais ajudam na cozinha, a preparar as refeições e até em algumas limpezas! A mãe, hoje em dia, também trabalha e costuma ser sempre a que exerce a maioria das tarefas domésticas. Auxilia os filhos na escola, também como o pai!"

[Catarina, Sintra]

"Hoje em dia, a mulher tem um papel igual ao do pai. Eu acho que a relação do pai deveria ser menos trabalho e mais vida amorosa. Há vezes em que as pessoas devem ser amadas, mas no caso do homem, parece que ele ama o seu trabalho. Eu acho assim, mas as pessoas é que sabem da sua vida. A minha mãe acha o mesmo que eu porque o meu pai também não trabalha muito e ela assim é mais feliz."

[Rafaela, 7.․ ano, Sintra]

"Isto é ser mau pai dando estes exemplos aos filhos, em vez de ajudarem as mães nos trabalhos domésticos não fazem nada, e as crianças mais tarde fazem as mesmas coisas com que foram criadas, e podem ser maus pais no futuro ou nunca se casam com ninguém, ou se casam e não têm filhos."

[Sebastião, 8.ำ ano, Lisboa]

\section{d) 0 "antes" e o "agora"}

19 Como já foi referido, os jovens revelam sentir a existência de algumas das tensões e dinâmicas culturais que continuam a afectar as atitudes e comportamentos relativamente à paternidade, nomeadamente através da referência frequente nas composições a um "antes" (onde um modelo de paternidade mais tradicional e menos "evoluído" seria a norma, e que ainda subsistirá em algumas famílias) e a um "agora" (onde os pais estarão, ou devem estar, mais envolvidos no dia-a-dia das suas famílias, cuidando dos seus filhos e colaborando nas tarefas domésticas), o que serve como indicador da coexistência cultural contemporânea de várias formas de representar e avaliar a pater- nidade, por vezes de cariz normativo contrastante. Os jovens chegam também a ques- tionar a verdadeira extensão das mudanças hipoteticamente ocorridas nas maneiras de ser pai, criticando, nomeadamente as raparigas, alguns dos comportamentos e atitudes que os seus próprios pais adoptam quando com eles se relacionam, por referência a formas eventualmente mais actuais e por eles desejáveis, sem que isso signifique que essas persistentes formas, eventualmente mais "tradicionais" de interacção, constituam a única dimensão das relações entre pais e filhos, tal como são percepcionadas por estes últimos. Cremos ser esse um indicador saliente de que os modelos sincréticos e plurais de paternidade serão 
hoje os mais frequentes nas famílias portuguesas contemporâneas com filhos pertencentes à mesma faixa etária dos jovens participantes neste estudo: o "antes" ainda bastante presente nas palavras e acções de muitos homens articulado de forma sincrética com elementos vários do "agora"; palavras e acções que são actualizadas quotidianamente de forma complexa pelos homens consoante as várias interacções em que entram, os vários contextos sociais através dos quais se movem e as circunstâncias sempre em mudança da vida de cada membro da família. É claro que esta constatação é conciliável com o facto de que alguns homens estão efectivamente a pôr em prática, com graus variados de sucesso, formas mais envolvidas e igualitárias de viver a paternidade.

"Hoje em dia as mulheres têm muitas actividades que alguns homens tinham antigamente. A sociedade moderna está muito modificada. Antigamente os homens eram os chefes-de-família, hoje em dia as mulheres já o são, em alguns casos."

[Ana, 7. ano, Chamusca]

"Antigamente, o homem assumia completo poder em tudo. A mulher servia como empregada e apenas para ter filhos, tomar conta deles e tratar das tarefas domésticas todo o dia em casa, enquanto o homem ia trabalhar e sempre teve muito mais liberdade na sociedade. Felizmente, hoje em dia já não é tanto assim onde vivemos, pois a mulher já tem um importante papel na sociedade e todas as tarefas já são divididas entre o casal e nós também devemos colaborar."

[Raquel, 7.ำ ano, Ourém]

"O desempenho da mulher era importante, pois, como o homem trabalhava, a mulher tinha de ficar em casa a tomar conta dos putos e da casa mas agora não, agora pai e mãe trabalham juntos, pois existem babysitters para tomar conta dos filhos. $O$ desempenho do pai agora é melhorado pois antigamente a mulher ficava em casa e o pai trabalhava. Agora os pais são mais cuidadosos pois prestam atenção aos filhos e mulheres."

[David, 8.ำ ano, Viseu]

\section{Considerações finais}

Como foi possível constatar, as perspectivas oferecidas pelos jovens acerca das famílias em geral, e das suas em particular, revelaram indicadores muito importantes para compreender sociologicamente de maneira mais abrangente as dinâmicas e interacções das famílias contemporâneas. Durante muito tempo encarados como sujeitos passivos de socialização, como receptáculos mais ou menos dóceis preparados para a inculcação de disposições, atitudes e comportamentos, as crianças e os jovens devem antes ser vistos como agentes criativos que influem decisivamente na construção quotidiana da vida familiar. A construção e mudança dos "papéis" parentais passa muito pelo estabelecimento, ao longo do tempo, de interacções intensas e recorrentes entre pais, mães, filhos e filhas, sendo que todos os elementos da família colocam quotidianamente em confronto atitudes e comportamentos multíplices que têm a sua origem em dinâmicas criadas no seio desse grupo, mas não só: também no trabalho, na escola, nos grupos de amigos, nos media, etc. Sendo a construção social de disposições e identidades multideterminada e sempre relacional, é necessário ter em conta que os papéis parentais se constroem também em interacção com os filhos; por sua vez, estes revelam possuir uma capacidade reflexiva notável para atribuírem sentidos diversos aos comportamentos e atitudes que observam todos os dias nos seus lares. Os jovens funcionam assim como agentes activos das dinâmicas e mudanças que ocorrem actualmente nas famílias e nas relações de género. 
O que de mais interessante merece ser destacado da análise aqui apresentada tem que ver com as pistas que aponta relativamente à complexidade cultural dos modelos e "papéis" parentais que os homens põem em prática quotidianamente. Segundo os textos elaborados pelos jovens, é notório que os pais de hoje se encontram na confluência de imagens múltiplas e, por vezes, contrastantes daquilo que significa ser "bom" e "mau" pai, ou daquilo que constitui ser um "novo" pai ou um pai "antiquado", em parte por referência aos seus próprios pais, mas também por influência de discursos e representações emanadas noutros domínios sociais. Essa complexidade simbólica é composta simultaneamente por representações mais tradicionais e mais "modernas" dos comportamentos e atitudes adequadas de paternidade, cabendo a cada indivíduo gerir e pôr em prática no dia-a-dia e ao longo do seu curso de vida estilos de ser pai sempre híbridos e plurais. Hoje em dia, essa "gestão" individual e interpessoal é enquadrada por múltiplas e rápidas transformações económicas, sociais e culturais que influem decisivamente na elaboração das disposições e identidades dos homens-enquanto-pais, destacando-se as variadas equações entre vida profissional e vida familiar e os factores culturais em mudança de elaboração das masculinidades.

\section{BIBLIOGRAPHY}

ADAMS, Michele e Scott Coltrane (2005), "Boys and men in families: the domestic production of gender, power and privilege”, in M. Kimmel, J. Hearn e R. W. Connell (orgs.), Handbook of Studies on Men and Masculinities: 230-248. Thousand Oaks, Sage Publications.

ALMEIDA, Ana Nunes de, Maria das Dores Guerreiro, Cristina Lobo, Anália Torres e Karin Wall (1998), "Relações familiares: mudança e diversidade", in J. M. Leite Viegas e A. Firmino da Costa (orgs.), Portugal, que Modernidade?: 45-78. Oeiras, Celta Editora.

BLÖSS, Thierry $(2001,2002)$, “L'égalité parentale au coeur des contradictions de la vie privée et des politiques publiques”, in Thierry Blöss (dir.), La Dialectique des rapports hommes-femmes: 45-70. Paris, PUF.

COLTRANE, Scott (2004), "Fathering: paradoxes, contradictions, and dilemmas", in Marilyn Coleman e Lawrence Ganong (orgs.), Handbook of Contemporary Families: Considering the Past, Contemplating the Future: 224-243. Thousand Oaks, Sage Publications.

COLTRANE, Scott e Michele Adams (1997), “Children and gender”, in Terry Arendell (ed.), Contemporary Parenting: Challenges and Issues: 219-253. Thousand Oaks, Sage Publications.

CONNELL, R. W. (2002, 2006), Gender, Cambridge, Polity Press.

CROMPTON, Rosemary (ed.) (1999), Restructuring Gender Relations and Employment: The Decline of the Male Breadwinner, Oxford, Oxford University Press.

GERSON, Kathleen (1997), “The social construction of fatherhood”, in Terry Arendell (ed.), Contemporary Parenting: Challenges and Issues: 119-153. Thousand Oaks, Sage Publications.

GUERREIRO, Maria das Dores, Ana Caetano e Eduardo Alexandre Rodrigues (2006), Famílias Contemporâneas e Relações de Género: Diversidade, Permanência e Mudança de Modelos Parentais, TYR - 
The Youngsters' Reply: Comparison of Different Parental Models, Relatório Nacional: Portugal, CIES-ISCTE.

KIMMEL, Michael S. (2000), The Gendered Society, Oxford, Oxford University Press.

LAROSSA, Ralph $(1988,1995)$, "Fatherhood and social change”, in Michael S. Kimmel e Michael Messner (eds.), Men's Lives: 448-460. Needham Heights, Allyn and Bacon.

LEANDRO, M. E. (2001), Sociologia da Familia nas Sociedades Contemporâneas, Lisboa, Universidade Aberta.

LEWIS, J. (2001), "The decline of the male breadwinner model: the implications for work and care", Social Politics, 8 (2): 152-170.

LUPTON, Deborah e Lesley Barclay (1997), Constructing Fatherhood: Discourses and Experiences, Londres: Sage Publications.

MARSIGLIO, William e Joseph Pleck (2005), “Fatherhood and masculinities”, in Michael S. Kimmel, Jeff Hearn e R. W. Connell (orgs.), Handbook of Studies on Men and Masculinities: 249-269. Thousand Oaks, Sage Publications.

MESSNER, Michael (1993), “'Changing men' and feminist politics in the United States”, Theory and Society, 22: 723-737.

PARSONS, Talcott (1965), "The normal American family", in S. Farber et al., Man and Civilization: 31-50. New York, McGraw-Hill.

PARSONS, Talcott e R. Bales (1955), Family Socialization and Interaction Process, New York, Free Press.

SAKKA, Despina e Vassiliki Deliyanni-Kouimtzi (2006), “Adolescent boys' and girls' views of fatherhood in the context of the changing women's position", Gender and Education, 18 (1): 51-74.

SARMENTO, M. J. (2000), "Sociologia da Infância: Correntes, problemáticas e controvérsias", Cadernos do Noroeste, v. 13, n. 2: 145-164.

SEGAL, Lynne (1990), Slow Motion: Changing Masculinities, Changing Men, New Brunswick, Rutgers University.

SEGAL, Lynne (1993), "Changing men: masculinities in context”, Theory and Society, 22 (5): 625-641.

TINKLIN, Teresa, Linda Croxford, Alan Ducklin e Barbara Frame (2005), "Gender and attitudes to work and family roles: the views of young people at the millennium", Gender and Education, 17 (2): 129-142.

TORRES, Anália (2001), Sociologia do Casamento: A família e a questão feminina, Oeiras: Celta Editora.

WALL, Karin e Maria das Dores Guerreiro (2005), “A divisão familiar do trabalho”, in Karin Wall (org.), Familias em Portugal: Percursos, Interacções, Redes Sociais: 303-362. Lisboa, ICS.

\section{NOTES}

1. O trabalho aqui apresentado insere-se no âmbito do projecto de investigação "The Youngsters' Reply: Comparison of Different Parental Models", desenvolvido em quatro países europeus: Portugal, Espanha, Itália e Grécia. Em Portugal, o projecto foi levado a cabo pelo Centro de Investigação e Estudos de Sociologia (CIES-ISCTE). A investigação envolveu a recolha de 792 composições, elaboradas por 811 jovens, em 23 escolas de todo o país. Para um maior 
aprofundamento da análise elaborada neste âmbito sobre os modelos de paternidade, e de parentalidade em geral, ver Guerreiro, Caetano e Rodrigues (2006).

\section{ABSTRACTS}

O presente estudo teve como principal objectivo identificar as imagens que os jovens portugueses têm acerca das suas famílias e sobre os modelos de paternidade que as enformam. Baseia-se numa análise qualitativa e integrada de 792 composições escri- tas por jovens estudantes de todo o país, de ambos os sexos e com idades compreendidas entre os 11 e os 14 anos. Com esta metodologia adoptou-se uma perspectiva raramente utilizada nos estudos sobre a família: captar a realidade familiar através dos discursos dos jovens. Enquanto agentes activos que contribuem para a construção da vida familiar e social, as suas opiniões e perspectivas sobre os processos de construção e mudança dos papéis parentais são fundamentais para compreender as famílias contemporâneas e as relações de género. Do conjunto de material analisado destacam-se as representações dos jovens relativamente à complexidade cultural dos modelos e "papéis" parentais que os homens põem em prática quotidianamente, encontrando-se na confluência de imagens múltiplas e, por vezes, contrastantes do que significa ser pai.

The main objective of this study was to identify the images that the Portuguese adolescents have of their families and the fatherhood models that inform those families. It is based on a qualitative and integrated analysis, on a national scale, of 792 essays written by 11-14 year old schoolchildren, of both sexes. This methodology adopted a perspective rarely taken in studies of the family: to capture the reality of the family through the discourses of the youth. As active agents who contribute to the construction of social and family life, their opinions and perspectives regarding the processes of construction and change associated with parental roles are fundamental to an understanding of contemporary families and gen- der relations. In the material analysed, taken as a whole, particular prominence is given to the young people's representations of the cultural complexity of the parental models and "roles" that men put into practice on a daily basis, as they find themselves at the point where multiple and frequently contrasting images of what it means to be a father converge.

La présente étude a pour principal objectif d'identifier les images que les jeunes portugais ont de leurs familles et des modèles de paternité auxquels elles obéissent. Elle se base sur une analyse qualitative et intégrée de 792 compositions écrites par des élèves de tout le pays, des deux sexes et âgés entre 11 et 14 ans. Cette méthodologie a permis d'adopter une approche rarement utilisée dans les études sur la famille : saisir la réalité familiale à travers les discours des jeunes. En tant qu'agents actifs qui contribuent à la construction de la vie familiale et sociale, leurs opinions et leurs perspectives sur les processus de construction et de changement des rôles parentaux sont fondamentales pour comprendre les familles contemporaines et les relations de genre. Sur l'ensemble du matériel ana- lysé, l'accent est mis sur les représentations des jeunes relatives à la complexité culturelle des modèles et des " rôles » parentaux que les hommes mettent en pratique quotidiennement, à la confluence d'images multiples et parfois contrastantes de ce que signifie être père. 
INDEX

Palavras-chave: papéis parentais, modelos de paternidade, relações de género, jovens

\section{AUTHORS}

\section{MARIA DAS DORES GUERREIRO}

CIES-ISCTE

maria.guerreiro@iscte.pt

\section{ANA CAETANO}

CIES-ISCTE

ana.caetano@iscte.pt

EDUARDO ALEXANDRE RODRIGUES

CIES-ISCTE

eduardo.rodrigues@iscte.pt 